\title{
Aplicação de teorias locacionais e políticas públicas para o varejo: Contorno Sul de Várzea Grande
}

Application of locational theories and discussion of public policies for businesses: South Contour of Varzea Grande.

Aplicación de teorias de ubicación y discurso de politicas públicas para comercios: Contorno de Sur de Várzea Grande

SOBREIRA, Cínthia Santiago; Especialista; Agência Nacional de Transportes Terrestres (ANTT)

cinthia.sobreira@,antt.gov.br

\section{Resumo}

Este trabalho objetiva ilustrar a aplicação de conceitos de localização de varejo e possibilidades de políticas públicas para melhorias de negócio no segmento rodoviário Contorno Sul em Várzea Grande, com vocação para atendimento a clientes transportadores de cargas. $O$ assunto pretende acrescentar elementos às discussões sobre temas urbanísticos relacionados ao comércio varejista a partir históricos da formação da via, teorias sobre localização, caracterização dos clientes, políticas voltadas ao atendimento desse segmento em relação a sua ocupação na cidade e impressões dos resultados da pesquisa.

Palavras-chave: Localização do comércio. Transporte rodoviário de cargas. Contorno Sul de Várzea Grande.

\section{Application of locational theories and discussion of public policies for businesses: South Contour of Varzea Grande.}

\begin{abstract}
This work aims to illustrate the application of retail location concepts and possibilities of public policies for business improvements in the South Contour of Varzea Grande, with a vocation to serve cargo transport customers. The subject intends to add elements to the discussions on urbanistic themes related to retail trade from historical formation of the road, theories about location, characterization of customers, policies aimed at serving this segment in relation to their occupation in the city and impressions of the research results.
\end{abstract}

Keywords: Trade location. Road freight transport. South Contour of Varzea Grande. Aplicación de teorias de ubicación y discurso de politicas públicas para comercios: Contorno de Sur de Várzea Grande.

\section{Resumen}

El objetivo deste estudio es el de demonstrar la aplicación de conceptos de ubicación del comercio al por menor y possibilidades de políticas públicas para mejorias en los negocios del sector carretero del Contorno Sur en Várzea Grande, con vocación para el atendimiento a clientes trasportadores de cargas. El tema 


\section{$\mathrm{VII} \mathrm{CINCCI}$}

VII Colóquio internacional sobre Comércio e Cidade

Fortaleza, 03 a 07 de Novembro de 2020

tiene la intención de añadir elementos a discursos sobre temas urbanos relacionados al comercio por menor con base en los históricos de formación de las vias carreterasteorias sobre ubicación, caracterización de los clientes, políticas direccionadas al atendimiento deste sector con relación a la ocupación en la ciudad y las influencias de los de resultados de la investigación.

Palabras clave: Ubicación del comercio. Transporte carretero de cargas del Contorno Sur de Várzea Grande 


\section{$\mathrm{VII} \mathrm{CINCCl}$}

VII Colóquio internacional sobre Comércio e Cidade

Fortaleza, 03 a 07 de Novembro de 2020

\section{Introdução}

Dentro das pesquisas já realizadas sobre o comércio varejista e sua interação com a cidade, podemos destacar alguns estudos estratégicos, tais quais a forma como o comerciante determina a localização do seu negócio e a existência de políticas públicas voltadas para a fixação e melhoria dessas atividades.

Conforme da bibliografia em voga, especificamente no Brasil, ainda há espaço para muito conteúdo a ser produzido. A pesquisa deseja acrescentar aos estudos o tema do comércio periférico em uma rodovia urbana destinada a tráfego de veículos pesados, no caso o Contorno Sul em Várzea Grande. O grupo sugerido é o de comerciantes e prestadores de serviços voltados ao transporte rodoviário de cargas.

\subsection{Contexto Histórico}

\subsubsection{Construção do Contorno Sul - MT 407, Rodovia dos Imigrantes}

Em 1985, as notícias oficiais citavam as obras do Contorno Sul como uma nova solução para o desvio de tráfego pesado em Cuiabá e em Várzea Grande (MATO GROSSO, 1985). Tudo foi materializado em 09 de novembro de 1986 (MATO GROSSO, 1986), com a inauguração do Contorno Sul, MT-407, CHAMADA Rodovia dos Imigrantes, em pista simples, com largura de $11 \mathrm{~m}$ e extensão de $28 \mathrm{~km}$, mais a construção da ponte JK sobre o Rio Cuiabá.

\subsubsection{Histórico da evolução produtiva da agropecuária}

A visão do governo à época estava acompanhando a tendência de aumento de produtividade agrícola no Estado de Mato Grosso. As técnicas de aumento de eficiência de produtividade desenvolvidas pela Empresa Brasileira de Pesquisa Agropecuária - EMBRAPA na década de 70 permitiram um aproveitamento melhor do solo do cerrado, contribuindo para a expansão de plantio de cerais em toda a região Centro-Oeste (VIEIRA FILHO, 2016).

As políticas públicas de financiamento evoluíram ao longo do tempo, partindo do Sistema Nacional de Crédito Rural - SNCR na década de 60, depois por financiamento privado, passando depois a ter mais apoio de bancos brasileiros (SILVA \& LAPO, 2012). A condição foi ainda melhorada após a estabilização da moeda brasileira.

Para efeito de conhecimento, na safra 2018/2019, a produção de soja chegou a 32,455 milhões de toneladas (EMBRAPA, 2019). Por conseguinte, o aumento da produção e das transações comerciais causou efeitos sobre a demanda de circulação de veículos transportadores de cargas. 


\subsubsection{Evolução da rodovia até a federalização}

O governo federal iniciou em 2012 uma nova etapa de investimentos em infraestrutura no país denominado Programa de Investimento em Logística - PIL, (AMATO \& MENDES, 2012). Entre eles, estava a concessão da rodovia BR-163/MT, que perpassa de norte a sul do Mato Grosso, principal corredor logístico de cargas do estado, associado à BR-364/MT, a qual é em parte sobreposta a ela.

A União federalizou a MT-407 por meio da portaria $n^{\circ} 169$ do Ministério dos Transportes, publicada no Diário Oficial da União em 22/10/2013 (G1, 2013) e ao segmento ficaram destinadas intervenções semelhantes aos demais segmentos da BR-163/MT, incluindo a duplicação dentro dos padrões de classe I-A, ou seja, pistas com duas faixas de $3,60 \mathrm{~m}$ de rolamento, faixa de segurança de $60 \mathrm{~cm}$, acostamento de $2,50 \mathrm{~m}$, mais canteiro central de $9 \mathrm{~m}$. A administração da concessão ficou a cargo da Concessionária Rota do Oeste S. A - CRO.

Nas imagens aéreas a seguir, vê-se destacado o Contorno Sul em amarelo, com as numerações de quilometragem referenciadas à BR-070/MT. Como se trata de estudo voltado ao segmento localizado em Várzea Grande, a imagem engloba o segmento entre o km 512 e o km 524 .

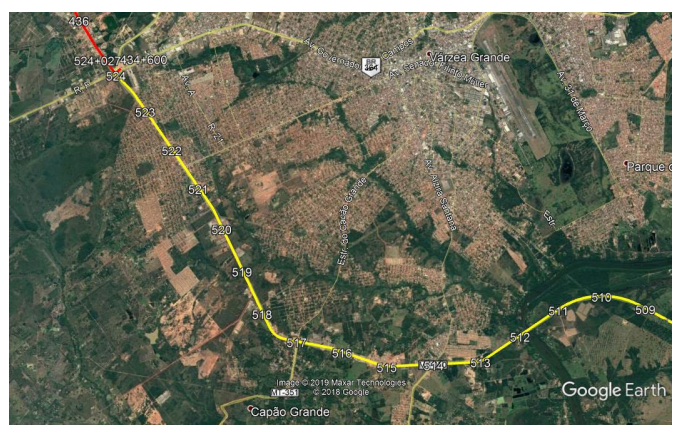

Figura 1: Imagem aérea do Contorno Sul no segmento de Várzea Grande, baseado em linhas georeferencidas entre o km 512 e o 524 da BR-070/MT

Fonte: Google Earth e ROTA DO OESTE (2019)

\subsubsection{Zoneamento urbano no município de Várzea Grande}

Dentro do atual zoneamento, as ocupações comerciais adjacentes à BR070/MT são misturadas ao tratamento dado às Zonas Especiais de Interesse Social, Zona Mista ou Zona Industrial (VÁRZEA GRANDE, 2012). A seguir está um recorte do zoneamento urbano em vigor, em que a cor vermelha corresponde à Zona Especial de Interesse Social (parcelamentos formais, ocupados irregularmente por população de baixa renda, passíveis de regularização), a cor abóbora é Zona Industrial 2 (categoria C, com área superior a $1000 \mathrm{~m}^{2}$ ), a cor rosa é Zona de Uso Misto (comércio direcionado aos bairros adjacentes e residências), e a cor amarela, Zona industrial (categorias não poluente A e B, até $1000 \mathrm{~m}^{2}$ ). 


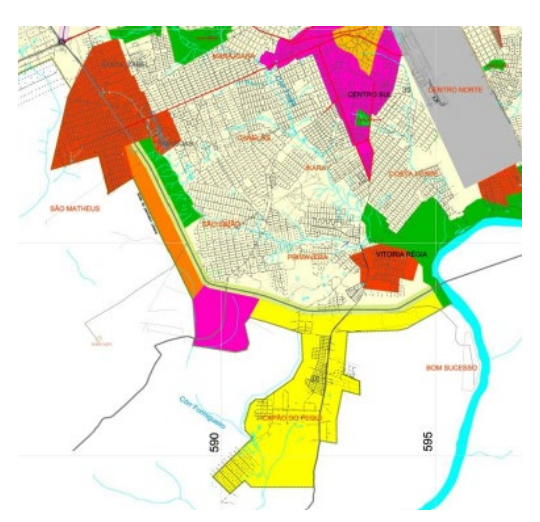

Figura 2: Recorte do mapa de zonemaneto urbano do município de Várzea Grande, anexo à Lei Complementar $n^{\circ} 3.727 / 2012$

Fonte: VÁRZEA GRANDE (2012)

\section{Fundamentos teóricos sobre a localização do comércio}

Considera-se que o conhecimento produzido em relação à compreensão das atividades de comércio e serviços ainda está em consolidação devido ao preconceito que esses negócios sofreram como atividades de relevância econômica e social (VARGAS, 2005). Em pesquisa bibliográfica, pelo menos nas literaturas disponíveis em português, os estudos de localização de varejo são escassos quanto ao um enquadramento e esquematização gerais, principalmente quanto aos comerciantes fora das grandes redes de abastecimento, supermercados e shoppings.

Dentro do conhecimento disponível, a coleta de informações, ainda que empírica, partirá da ciência prévia de fatores que interferem na localização citados em VARGAS (2018) (16). São eles:

Quanto aos fatores que podem interferir na escolha da localização, são eles:

Trabalho: disponibilidade de mão-de-obra voltada ao negócio.

Capital: propriedade, bens e disponibilidade financeira.

Demanda: a procura pelo produto e o serviço oferecido.

Transportes: formas e custos de deslocamento dentro do processo do negócio, seja de cargas ou pessoas.

Fluxos: circulação de insumos, informação, dinheiro, pessoas (movimentação próxima ao negócio) e mercadorias.

Organização empresarial: depende de o controle do negócio estar associado ou não ao proprietário.

Políticas públicas: são ações do governo que influenciam os negócios, tais como políticas de desenvolvimento voltadas à geração de emprego, balança comercial, entre outras. Também podem ser diretas, tais como legislação voltadas a tributos, ou indiretas, como a construção de obras.

Contexto sociocultural: dependem de formação cultural, étnica e religiosa.

Tecnologia: desenvolvimento de ferramentas para aprimorar o atendimento às demandas do negócio, bem como a geração de novos produtos.

Espaço físico: disponibilidade territorial para o negócio. 


\subsection{Caracterização do tráfego da Rodovia dos Imigrantes e ocupações comerciais adjacentes}

\subsubsection{Tráfego}

Foi realizada consulta à base de dados de tráfego e arrecadação da concessionária Rota do Oeste. Os dados obedecem ao Contrato de Concessão Edital $n^{\circ}$ 003/2013, firmado entre a União e a concessionária, são estipuladas 10 categorias de veículos correspondentes à sua capacidade e número de eixos, variando de 2 a 8 eixos, com rodagem simples à dupla. A décima categoria trata de veículos oficiais, que na prática, são enquadrados na capacidade dos demais veículos, tendo como registro especial a condição de isentos.

Para veículos com mais de seis eixos, sua classificação deve ser enquadrada como uma extensão da categoria $n^{\circ} 8$. Nesse sentido, o número de eixos adicionais deve ser multiplicado pelo fator da categoria $n^{0} 1$. Para a representação desses grupos adicionais, utilizasse como representação simbólica as classificações 61 (6eixos+1), 62(6 eixos+2), 63 (seis eixos +3 ) e 64 (6 eixos +4 ).

Como fonte de dados, será tomado o tráfego das praças de pedágio mais próximas, as quais são a Praça de Pedágio P4 Santo Antônio do Leverger, km 302 da BR-163/MT, ao sul do segmento da Rodovia dos Imigrantes, e a Praça de Pedágio P5 Jangada, km 398 da BR-163/MT ao norte.

Foram coletados os dados de um ano, no intervalo entre julho de 2018 e junho de 2019 , contemplando todas as sazonalidades de um ano. O resultado para cada praça foi o seguinte está descrito na tabela a seguir.

Tabela 1 - Volume de veículos nas Praças de Pedágio P4 e P5

\begin{tabular}{|c|c|c|}
\hline \multicolumn{3}{|l|}{ Período: julho/2018 a junho de 2019} \\
\hline \multirow{3}{*}{$\begin{array}{l}\text { Categoria } \\
1 \text { - Automóvel, caminhonete, furgão (2 eixos) }\end{array}$} & \multicolumn{2}{|c|}{ Volume de veículos } \\
\hline & P4 & P5 \\
\hline & 1.507 .529 & 538.180 \\
\hline 2 - Caminhão leve, ônibus caminhão trator e furgão (2 eixos) & 230.187 & 124.515 \\
\hline $\begin{array}{l}3 \text { - Automóvel com semi-reboque e caminhoneta com semi- } \\
\text { reboque ( } 3 \text { eixos) }\end{array}$ & 10.462 & 5.057 \\
\hline $\begin{array}{l}4 \text { - Caminhão, caminhão trator, caminhão trator com semi- } \\
\text { reboque e ônibus (3e) }\end{array}$ & 251.552 & 137.443 \\
\hline 5 - Automóvel com reboque e caminhoneta com reboque (4e) & 2.397 & 903 \\
\hline $\begin{array}{l}6 \text { - Caminhão com reboque, caminhão trator com semi- } \\
\text { reboque }(4 \mathrm{e})\end{array}$ & 296.764 & 212.898 \\
\hline $\begin{array}{l}7 \text { - Caminhão com reboque, caminhão trator com semi-reboque } \\
(5 \mathrm{e})\end{array}$ & 196.317 & 144.477 \\
\hline $\begin{array}{l}8 \text { - Caminhão com reboque, caminhão trator com semi-reboque } \\
(6 \mathrm{e})\end{array}$ & 569.424 & 395.112 \\
\hline 9 - Motocicletas, motonetas e bicicletas a motor (2e) & 62.511 & 26.476 \\
\hline $\begin{array}{l}61 \text { - Caminhão com reboque, caminhão trator com semi- } \\
\text { reboque mais } 1 \text { eixo }\end{array}$ & 354.036 & 305.467 \\
\hline
\end{tabular}




\begin{tabular}{|c|c|c|}
\hline $\begin{array}{l}62 \text { - Caminhão com reboque, caminhão trator com semi- } \\
\text { reboque mais } 2 \text { eixos }\end{array}$ & 4.240 & 3.293 \\
\hline $\begin{array}{l}63 \text { - Caminhão com reboque, caminhão trator com semi- } \\
\text { reboque mais } 3 \text { eixos }\end{array}$ & 454.280 & 418.559 \\
\hline $\begin{array}{l}64 \text { - Caminhão com reboque, caminhão trator com semi- } \\
\text { reboque mais } 4 \text { eixos }\end{array}$ & 187 & 98 \\
\hline Total & 3.939 .886 & 2.312 .479 \\
\hline
\end{tabular}

Fonte: ROTA DO OESTE (2019)

Para ilustrar o posicionamento das praças de pedágio, segue a figura esquemática da localização das praças na rodovia.

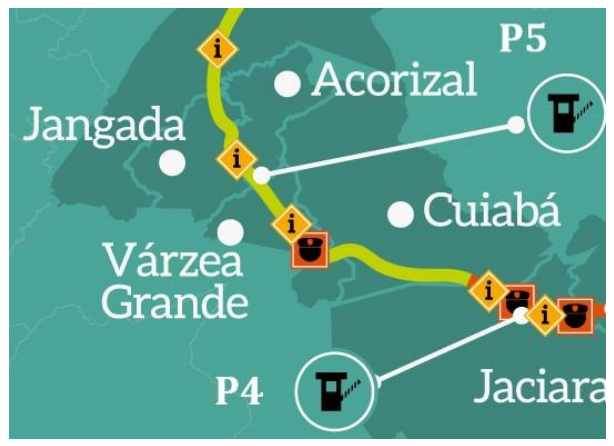

Figura 3: Recorte retirado de mapa esquemático da rodovia com a posição das prças de pedágio $\mathrm{P} 4$ e $\mathrm{P} 5$.

Fonte: ROTA DO OESTE (2019)

Se considerarmos que a partir da categoria 2 (excluindo a 9), iniciam os veículos de cargas, ainda que somados os ônibus e alguns tratores, percebe-se que veículos pesados são maior número em todas as praças. Se ainda forem somadas apenas as categorias a partir de 4 eixos (veículos comumente destinados ao transporte da produção agropecuária e insumos e com restrições de circulação urbana), percebe-se que em todos os casos a somatória ainda é superior aos veículos da categoria 1.

A fotografia a seguir ilustra um dia de movimento de veículos convencional na rodovia registrado em 27/05/2020.

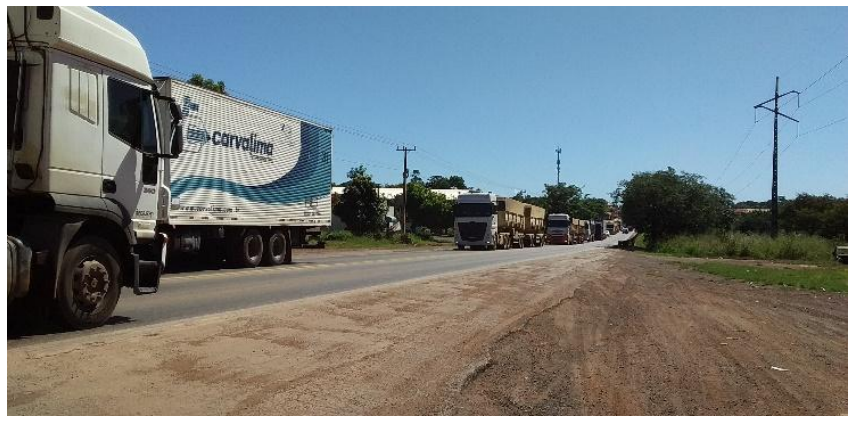

Figura 4: Tráfego de caminhões e carretas no Contorno Sul.

Fonte: Da autora, 2020. 


\subsubsection{Tipos de ocupações comerciais}

A fim de vincular os tipos de veículos preponderantes na rodovia, no caso os de transporte de carga, aos tipos de ocupações comerciais e de serviços adjacentes, no dia 27/05/2020 foi realizado um levantamento visual no Contorno Sul. Os dados foram coletados do $\mathrm{km} 513 \mathrm{em}$ diante, posto que até o $\mathrm{km} 512$ a contribuição seria desprezível devido à área de aproximação com a ponto sobre o Rio Cuiabá.

Os resultados foram elencados na tabela a seguir, desprezando terrenos e edificações sem uso.

\section{Tabela 2 - Contagem e classificação dos estabelecimentos de comércio e} serviços

\begin{tabular}{|l|r|}
\hline Tipo de comércio/serviço & Quantidade \\
\hline Administradora de frotas de automóveis & 1 \\
\hline Aluguel de tratores e equipamentos & 1 \\
\hline Borracharia & 7 \\
\hline Combustíveis e complexo de serviços associados & 9 \\
\hline Comércio e armazenagem de milho e soja & 1 \\
\hline Conserto de sistema de freios, suspensão e alinhamento entre outros & 9 \\
\hline Conserto de sistema de freios & 2 \\
\hline Construtora & 2 \\
\hline Distribuição e venda de pneus & 1 \\
\hline Distribuidora de marcas & 1 \\
\hline Drogaria & 2 \\
\hline Fornecimento de blocos de concreto & 1 \\
\hline Fornecimento de brita, areia, aterro e cascalho & 1 \\
\hline Fornecimento de carroceria tanque & 1 \\
\hline Fornecimento de ligante e misturas asfálticas & 1 \\
\hline Fornecimento de peças automotivas & 5 \\
\hline Fornecimento de peças automotivas usadas & 1 \\
\hline Fornecimento de peças em madeira para construção & 1 \\
\hline Fornecimento e instalação de caixas de cozinha & 1 \\
\hline Fornecimento e instalação de carrocerias & 1 \\
\hline Fornecimento e instalação de climatizadores ecológicos prediais & \\
\hline Fornecimento e instalação de equipamentos para freios e sistemas & \\
\hline Fornecimento e instalação de escapamento & \\
\hline
\end{tabular}




\begin{tabular}{|c|c|}
\hline Fornecimento e instalação de lonas para carrocerias & 1 \\
\hline Fornecimento e instalação de peças automotivas em fibra & 4 \\
\hline Fornecimento e instalação de peças automotivas em fibra e lonas & 1 \\
\hline $\begin{array}{l}\text { Fornecimento e instalação de peças automotivas em fibra e } \\
\text { veiculares }\end{array}$ & 1 \\
\hline Fornecimento e instalação de películas veiculares & 1 \\
\hline Fornecimento e instalação de rastreadores & 1 \\
\hline Fornecimento e instalação de tacógrafos & 2 \\
\hline Fornecimento, instalação e manutenção de sistemas de injeção & 2 \\
\hline $\begin{array}{l}\text { Fornecimentos e instalação de artefatos de borracha para veículos e } \\
\text { máquinas }\end{array}$ & 1 \\
\hline $\begin{array}{l}\text { Fornecimentos e instalação de carrocerias, semirreboques e } 2^{\circ} \text { eixo } \\
\text { direcional }\end{array}$ & 1 \\
\hline Fornecimentos e instalação de tapeçaria para caminhões & 3 \\
\hline Funilaria e recuperação de carrocerias & 3 \\
\hline Hotelaria & 3 \\
\hline Indústria de artefatos de cerâmica & 1 \\
\hline Instalação e fornecimento de ar condicionado & 4 \\
\hline Lanchonete & 2 \\
\hline Lavagem de veículos & 3 \\
\hline Lavagem de veículos e lanchonete & 1 \\
\hline Manutenção de sistemas elétricos & 2 \\
\hline Mecânica & 10 \\
\hline Mecânica (inclui tratores) & 1 \\
\hline Mecânica de automóveis & 1 \\
\hline Mecânica e manutenção de sistemas elétricos & 1 \\
\hline Mecânica especializada em marca & 3 \\
\hline Reparo em eixos cardans & 1 \\
\hline Reparo em injeções eletrônicas & 1 \\
\hline Reservatório para distribuição de água & 1 \\
\hline Restaurante & 6 \\
\hline Serviço de instalação e reforma de carroceira do tipo boiadeira & 1 \\
\hline Serviço de retificação de motores & 1 \\
\hline Serviço de usinagem de peças & 1 \\
\hline
\end{tabular}




\begin{tabular}{|l|r|} 
Serviços de borracharia, auto elétrica, borracharia e mecânica & 1 \\
\hline Supermercado & 1 \\
\hline Transporte de Cargas & 3 \\
\hline Venda de caminhões & 1 \\
\hline Venda e manutenção de barcos & 1 \\
\hline Venda hortifruti & 1 \\
\hline Total de estabelecimentos & $\mathbf{1 3 1}$ \\
\hline
\end{tabular}

Dentro desse universo, pode ser considerado que apenas as categorias a seguir não têm um relacionamento estrito com o transportador de carga como cliente, os quais são: a administradora de frotas de automóveis; o reservatório; e a loja de venda de barcos. Isso representa apenas $2,29 \%$ do universo de dados.

Algumas categorias podem também ter a clientela dos bairros, tais como supermercado, restaurante e drogaria. Mas considerando a função ambígua dos estabelecimentos, serão contados no cômputo geral de atendimento aos transportadores de cargas.

Operadores logísticos e construtoras foram colocados como conectados ao universo de transporte de carga pelo fato de que, embora não trabalhem para esses clientes em si, sua cadeia produtiva depende fortemente da presença desse tipo de transporte.

A fotografa a seguir ilustra um típico movimento em comércio e serviços para o cliente de transporte de carga.

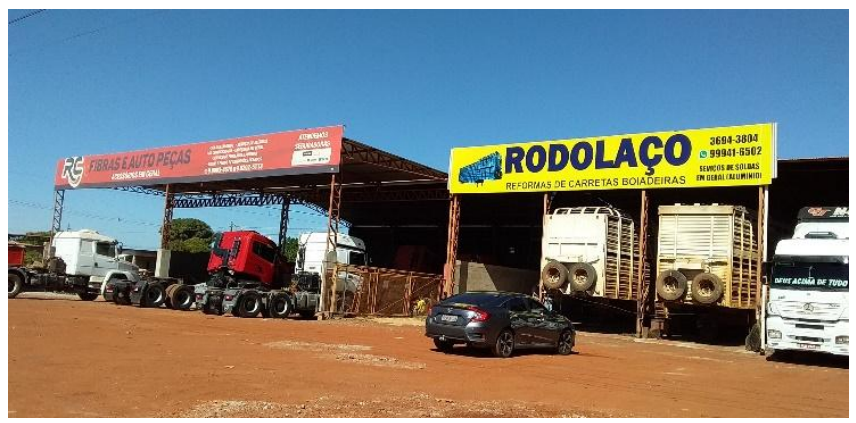

Figura 5: Estabelecimentos de vendas de peças de fibras, reforma de carrocerias e instalação de lonas.

Fonte: Da autora, 2020.

\section{Pesquisa de campo}

A pesquisa partiu da elaboração de um questionário com poucas perguntas, elaboradas com possibilidade de respostas amplas, abstraindo delas o conteúdo aplicável à temática do trabalho, o qual trata da maneira como o varejista localiza o 
seu negócio e que tipo de política pública pode ser direcionada para ele do ponto de vista urbanístico ou até além dele. O foco foi direcionado ao comerciante e prestador de serviço individual dono de pequenos negócios.

O questionário continha as seguintes questões:

Nome Fantasia:

a) Tipos de serviços e/ou mercadorias oferecidas:

b) Data de início do negócio:

c) Quais as principais motivações para a abertura do negócio:

d) Enfrenta alguma dificuldade para manter o negócio?

e) Em algum momento passado chegou a ser beneficiado por algum programa de governo voltado ao seu negócio? Qual?

f) Que tipo de intervenção/política pública seria interessante para beneficiar o seu negócio?

Os dados foram colhidos no dia 06/08/2019, em horário comercial. O número de estabelecimento procurados se restringiu às possibilidades oferecidas pelo dia, tais como locais onde os proprietários estavam presentes para dar informações, área disponível para estacionamento e respeitando o ritmo da atividade no estabelecimento.

Foram ouvidos no total 7 estabelecimentos em locais diversos. De acordo com os serviços e mercadorias oferecidas, são divididos nos seguintes tipos:

1 restaurante

1 hotel

1 oficina de funilaria

1 oficina de instalação de caixas de cozinha

3 oficinas de serviços de mecânica em geral para caminhões e carretas

O tempo de funcionamento do estabelecimento era muito variável. O universo foi de um a 29 anos, este último, bem próximo do início da Rodovia (uma das oficinas mecânicas).

As respostas quanto à motivação também foram variadas para cada estabelecimento. As repostas básicas de cada um foram:

a) Por acaso (restaurante);

b) Para diversificar negócios, como possibilidade de aluguel imobiliário (hotel);

c) Necessidade (oficina de funilaria);

d) Já tinha experiência com móveis e desejava aplicar para caminhões e carretas (oficina de caixa de cozinha);

e) Adaptação da experiência em mecânica de caminhões e como motorista para a abertura de um negócio próprio (oficina mecânica 1);

f) Aproveitar a oportunidade do surgimento da rodovia para oferecer serviço mecânicos pesados (oficina 2);

g) Continuação de negócios da família (oficina 3).

Quanto às dificuldades para manter o negócio, apenas dois estabelecimentos disseram que não tinham dificuldades para manter o negócio. Entre os demais comerciantes, foram apontadas uma ou mais dificuldades, as quais são organizadas a seguir em ordem decrescente:

a) Burocracia pesada e mal atendimento para obtenção de alvarás (3 apontamentos);

b) Carga tributária pesada (3 apontamentos); 
c) Ausência de financiamento em boas condições para o seu negócio (2 apontamentos);

d) Dificuldade de encontrar mão-de-obra qualificada para mecânica de veículos pesados (2 apontamentos);

e) Diminuição de clientes após crise econômica dos últimos anos (1 apontamento);

f) Diminuição de clientes devido à alta do diesel (1 apontamento);

g) Preço da energia muito alto (1 apontamento);

h) Ausência de rede de coleta municipal de esgoto (1 apontamento);

i) Trânsito lento de veículos, já que a rodovia ainda não é duplicada (1);

j) Desconhecimento do poder público quanto ao funcionamento dos negócios (1 apontamento).

A respeito dos benefícios recebidos eventualmente por programas de governo, todos foram unânimes em responder que em nenhum momento foram beneficiados por governo de forma direta em programa voltados para seus negócios em nenhuma esfera de poder.

Perguntados sobre a intervenção/política pública que beneficiasse o seu negócio, apenas um comerciante disse que não necessitaria de algo para o seu negócio. Sobre os demais a ordem de apontamentos das respostas foi a seguinte:

a) Financiamentos voltados a ampliação do seu negócio (2 apontamentos);

b) Redução de impostos e taxas (1 apontamento);

c) Tabelamento do frete (1 apontamento);

d) Mais segurança pública (1 apontamento);

e) Redução de preço de combustível para melhoria da compensação pelo frete e retorno dos clientes transportadores autônomos (1 apontamento);

f)Tabelamento do frete para melhor pagamento dos transportadores (1 apontamento);

g) Financiamento para aquisição de equipamentos par geração de energia solar (1 apontamento);

h) Pavimentação para o bairro, com rede de esgoto (1 apontamento).

Ao longo do processo de diálogo com o dono do negócio, algumas informações acabaram aparecendo de forma complementar. Quanto ao restaurante, por exemplo, as informações do proprietário acabaram dizendo que sua clientela contemplava não só os passantes pela rodovia, mas também as pessoas que trabalhavam nos negócios vizinhos e moradores do bairro.

\section{Análises}

\subsection{Correlação com conceitos}

Do ponto de vista das teorias locacionais explicitadas, percebe-se um mix de impressões partindo do ponto de vista das respostas motivacionais dos negócios, as quais não tem a ver com planejamentos prévios estruturados, mas uma conjugação entre vocação pessoal e oportunidade diante de uma política pública, a qual trata da construção da própria rodovia e dos clientes que passam por ela.

Dentre os fatores de localização, os mais evidentes abstraídos das respostas foram:

Demanda: a visualização das ocupações comerciais da rodovia, a observação do tráfego passante, do estacionamento de veículos na faixa de domínio e as 
informações retiradas junto à concessionária caracterizaram de forma bastante explícita a procura dos serviços oferecidos junto à rodovia, o que confirma a adequação dos negócios ao contexto.

Fluxos: fluxo intenso passante de veículos de carga.

Organização empresarial: os negócios eram apenas de um proprietário, que, quando não administrava apenas sozinho, tinha membros da sua família na gerência do negócio.

Políticas públicas: afora a oportunidade indireta que a rodovia causou, a resposta chegou a revelar um certo desamparo com relação aos comerciantes. Esse item terá destaque mais adiante.

Espaço físico: embora seja um fator sem abstração do questionário, era visto logo que o negócio era visitado. Os estabelecimentos em geral tinham uma boa área de estacionamento em seu negócio. No entanto, alguns deles usufruíam da área adjacente à rodovia para atender seus clientes.

\subsection{Políticas públicas}

Esta pesquisa não procura condenações, mas enxerga patamares de processos decisórios na administração voltados a obras e ao simples acompanhamento do zoneamento. As razões podem ser diversas, tais como ausências de políticas federais de orientação aos municípios, restrições orçamentárias, ou até o desconhecimento de diferentes estratégias voltadas ao varejo.

Apesar disso, as ações primárias do município foram citadas em uma das respostas em que o comerciante necessita do aprimoramento da rede coletora de esgoto para a melhoria do seu negócio.

Quanto aos assuntos levantados nos questionários, um tipo de política essencial é a racionalização das obtenções de alvarás, cujos processos são morosos e complexos.

Já outras ações têm caráter macro e envolvem a conjugação de esforços da União, Estados e municípios, que são a diminuição das cargas tributárias.

Foram citadas também mais possibilidades de financiamento para esses negócios. Em informações complementares obtidas dos diálogos adicionais ao questionário, alguns cresceram mais lentamente por contar apenas com a organização dos recursos próprios.

Também existem as reclamações de falta de mão-de-obra não necessariamente indicam falta de conhecimento. Até pode ser uma das opções, mas também pode ser a não atratividade entre remuneração e o trabalho.

As políticas voltadas ao tabelamento de fretes também foram citadas. São de ordem macro e associadas ao governo federal. Nesse sentido, uma política de governo que pense em mercado livre para o frete, transportadores mais frágeis deixam de viajar e ir às oficinas.

O interessante também foi a pouca reclamação quanto à necessidade de melhorias na rodovia, a não ser quanto à ampliação para a fluidez, a qual beneficia o próprio comerciante quando precisa se deslocar para realizar atividades acessórias ao seu negócio. Visualmente, o entorno da pista tem a movimentação bastante tumultuada devido à falta de soluções quanto aos acessos irregulares. 


\section{Considerações finais}

Baseado nas pesquisas de dados, bibliografias e de dados em campo, foi possível estabelecer algumas correlações entre os conceitos locacionais de varejo para uma realidade de rodovia em área periférica, cujo vínculo entre fluxo e serviços oferecidos ficou caracterizado.

O fato de não haver políticas urbanísticas voltadas ao tipo de varejo trabalhado para essa pesquisa já era esperado. Conforme visto anteriormente, o Brasil ainda caminha nos aspectos da organização de políticas que conciliem o apoio mais profundo ao varejista no contexto de ordenação e desenvolvimento econômico urbano. Ainda mais dentro desse universo periférico que se apresenta no trabalho, uma rodovia que contorna a cidade, mesmo com intensos sinais de trocas comerciais devido à alta movimentação de clientes.

\section{Agradecimentos}

Foi essencial a colaboração da Concessionária Rota do Oeste S.A, a qual forneceu dados numéricos e fotografias que retrataram a realidade do segmento rodoviário objeto do estudo.

\section{Referências}

AMATO, Fábio \& MENDES, Priscilla. Governo lança pacote de concessão de R\$ 133 bi para rodovias e ferrovias. G1. Brasília, 15 ago. 2012. Disponível em http://g1.globo.com/economia/noticia/2012/08/governo-lanca-pacote-de-r-133bilhoes-para-rodovias-e-ferrovias.html . Acesso em 01 ago. 2019.

CONCESSIONÁRIA ROTA DO OESTE S.A - CRO. Relatório Técnico Operacional Físico Financeiro. Cuiabá, mai 2019, p. 8.

EMPRESA BRASILEIRA DE PESQUISA AGROPECUÁRIA - EMBRAPA , A Soja em Números. Brasília: EMBRAPA. Jun. 2019. Disponível em: https://www.embrapa.br/soja/cultivos/soja1/dados-economicos . Acesso em: 01 ago. 2019.

Lei que federalizada rodovia em MT é publicada no Diário da União. G1. Brasília, 22 out. 2013. Disponível em http://g1.globo.com/mato-grosso/noticia/2013/10/leique-federalizada-rodovia-em-mt-e-publicada-no-diario-da-uniao.html . Acesso em 01 ago. 2019.

MATO GROSSO. Governo constrói nova ponte sobre o Rio Cuiabá. Diário Oficial do Estado de Mato Grosso. Cuiabá, MT. Ano XCV, n. 19.342, p. 2, 19 set. 1985.

MATO GROSSO. Contorno Sul entra em operação. Diário Oficial do Estado de Mato Grosso. Cuiabá, MT. Ano XCVI, n. 19.672, p. 1, 10 nov. 1986.

SILVA, Felipe Prince \& LAPO, Luis Eduardo Rebolo. Modelos de financiamento da cadeia de grãos no Brasil. In: $2^{a}$ CONFERÊNCIA DE GESTÃO DE RISCOS E 
COMERCIALIZAÇÃO DE COMMODITIES. São Paulo: BM\&F BOVESPA. 2012, p. 4-8.

VARGAS, Heliana Comin. Comércio e serviços varejistas nos estudos urbanos e a complexidade na produção do conhecimento. In: I COLÓQUIO INTERNACIONAL DE COMÉRCIO E CIDADE: UMA RELAÇÃO DE ORIGEM. São Paulo. Set. 2005. Anais do II CinCci. São Paulo: FAUUSP-LABCOM, mar. 2008, p. 2-3.

VARGAS, Heliana Comin. Espaço terciário: o lugar, a arquitetura e a imagem do comércio. 2. ed. Barueri: Manole, 2018, p. 32-67.

VIEIRA FILHO, José Eustáquio Ribeiro. A fronteira agrícola brasileira: redistribuição produtiva, efeito poupa-terra e desafios estruturais logísticos. In: Agricultura, transformação produtiva e sustentabilidade. Brasília: IPEA. 2016. p.93. 